\title{
Effect of south winds on daily mortality in Athens
}

\author{
N. Papadopoulou ${ }^{1, *}$, Y. Tountas ${ }^{1}$, V. Sypsa ${ }^{2}$, K. Katsouyanni ${ }^{2}$, A. Analitis ${ }^{2}$, \\ P. Kassomenos ${ }^{3}$
}

\author{
${ }^{1}$ Center for Health Services Research, Department of Hygiene and Epidemiology, Medical School, University of Athens, \\ 25 Alejandroupoleos Street, 11527 Athens, Greece \\ ${ }^{2}$ Department of Hygiene, Epidemiology and Medical Statistics, Medical School, University of Athens, 75 Mikras Asias Street, \\ 11527 Athens, Greece \\ ${ }^{3}$ Laboratory of Meteorology, Department of Physics, University of Ioannina, University Campus, 45110 Ioannina, Greece
}

\begin{abstract}
The present study investigated the possible effects of south winds on daily mortality in Athens during the period 1983-1991. The mortality data were assembled from the Athens city registry and registries of the adjacent municipalities. The mean daily dry bulb and dew point temperature, as well as the wind speed and duration for which the south winds were blowing, were recorded by the Institute of Meteorology and Physics of the Atmospheric Environment of the National Observatory of Athens. Temperature, dew point temperature, seasonal and long-term patterns, as well as other potential confounders, have been adjusted for. Synoptic circulation patterns over Athens have been taken into account. Regression modelling was used for the analysis adjusting for autocorrelation where appropriate. When the south winds were added to the basic model (adjusting for year, season, day of the week, temperature, dew point temperature and black smoke), an increase of $3.2 \%$ in the daily mortality (95\% CI: 1.4 to $4.8 \%$ ) was observed on the days when south winds were blowing, compared to the days without a south wind. When a variable for southwesterly synoptic flow was also included in the model, the effect of south winds remained approximately the same: a $2.9 \%$ increase in daily mortality (95\% CI: 1.9 to $4.7 \%$ ), whilst the effect of the southwesterly synoptic flow was also significant and of similar magnitude (a 3.4\% increase in the daily number of deaths, $95 \%$ CI: 1.1 to $5.8 \%$ ). Longer duration and higher wind speed were also associated with increased mortality. In conclusion, adjusting for all known confounders, it was found that the days on which south winds blow are characterized by increased mortality in Athens.
\end{abstract}

KEY WORDS: South winds $\cdot$ Mortality $\cdot$ Southwesterly synoptic flow $\cdot$ Temperature $\cdot$ Dew point temperature $\cdot$ Black smoke

\section{INTRODUCTION}

Many studies have reported associations on the influence of the atmospheric environment, and in particular changes in the weather, with various health effects, including an increase in mortality (Marmor 1975, The Eurowinter Group 1997, Keatinge et al. 2000).

The awareness of the effects of weather on health is rooted in the distant past. Hippocrates was among the first to associate climatic conditions with health, maintaining that illnesses are induced mainly by seasonal changes and during the seasons by the alternation of cold and hot weather. He believed that according to rain or drought, humidity or dryness of the atmosphere, it is possible to predict disease patterns. Specifically, he reported that the south winds generate adverse health conditions (Edelstein 1931, Sigerist 1961).

Following these reports, Galenus, an eminent doctor of the Roman period maintained that the 'left wind' is the clean wind free of vapours from swamps or sewage and drains, whilst the unclean wind had negative effects on health. Later, the sophist Adamantios referred to the winds and specifically to the pathological effects of the hot and humid south winds in contrast 
to the healthy north winds, stressing at the same time the importance of the place of origin of the winds, indicating that this could explain the transmission of infectious diseases by the moving masses of air (Olivieri 1935).

Interest in the role of environmental factors on health subsequently declined. Only in recent years has attention returned to the concept, with the development of the multifactorial explanations and the formulation of new ecological models for the determination of the factors that affect health.

Research has focussed on overall effects of meteorological and climatic factors, using synoptic indices or categories derived from the synthesis of different meteorological variables. The whole topic has attracted greater interest due to the recent concern with climatic change (Kalkstein 1991, Pope \& Kalkstein 1996, Kalkstein \& Greene 1997, Curriero et al. 2002). Kassomenos et al. (2001) found that the southwesterly synoptic flow, which includes the transportation of warm and humid air masses from the Mediterranean and North Africa, is associated with increased mortality in Athens.

The present study investigated the possible effects of south winds on daily mortality in Athens during the period 1983-1991, controlling for confounding factors, including temperature and dew point temperature, increases in which are characteristic of the south winds in the area. In this way, it was possible to quantify the independent effect of the south winds, over and beyond the reported associations with temperature, dew point temperature and synoptic weather categories.

\section{MATERIALS AND METHODS}

\subsection{Topography and climate}

Athens lies in a valley surrounded by 3 mountains and the sea. The major axis of the valley runs from northeast to southwest for about $30 \mathrm{~km}$. The climate of Athens is Mediterranean. The mean daily temperature during the winter months is $9.9^{\circ} \mathrm{C}$, and the minimal daily temperature falls below $0^{\circ} \mathrm{C}$ only 2 or 3 times per year. During the summer months the mean daily temperature is $25.8^{\circ} \mathrm{C}$, and the mean value of the maximum daily temperature slightly exceeds $31^{\circ} \mathrm{C}$. Insolation is strong, with average daily values of $22 \mathrm{MJ} \mathrm{m}^{-2}$ in the summer and $8 \mathrm{MJ} \mathrm{m}^{-2}$ in the winter. The prevailing wind direction is north-northeast at the end of summer, in autumn and in winter, and south-southwest in spring and at the beginning of the summer (Touloumi et al. 1994).

Statistics on the daily number of deaths from all causes for the period 1983-1991 were assembled by the Athens city registry and the registries of the adja- cent municipalities. All deaths occurring in these areas are routinely recorded in the corresponding municipal registries (Touloumi et al. 1994).

The mean daily dry bulb and dew point temperature $\left({ }^{\circ} \mathrm{C}\right)$, the wind direction per hour (south vs. other), wind velocity $\left(\mathrm{m} \mathrm{s}^{-1}\right)$ and the duration (h) for which the south winds were blowing, were obtained from the Institute of Meteorology and Physics of the Atmospheric Environment of the National Observatory of Athens, which measures on a hill in the centre of Athens (annual climatological bulletins).

Black smoke (24 h average) was used as an indicator of ambient particle concentrations; measurements were taken from 5 monitoring stations run by the Ministry of Environment, Planning and Public Works (Touloumi et al. 1994).

Synoptic circulation patterns over Athens have been examined by Kassomenos et al. $(1998,2001)$. The classification of the large-scale atmospheric circulation patterns in the lower troposphere was carried out at the isobaric levels of 850 and $700 \mathrm{hPa}$ (about 1500 to $3000 \mathrm{~m}$ above mean sea level); the isobaric level of $700 \mathrm{hPa}$ was used as auxiliary. These isobaric levels characterize the large-scale atmospheric circulation, independent of topographic effects (the mountain tops around Athens are lower than $1500 \mathrm{~m}$ ); 8 categories have been defined a priori according to the general circulation pattern, the position of the synoptic systems with respect to Athens, and the orientation of the trough or ridge axis. These were statistically distinct with respect to their thermodynamic characteristics and are shown in Table 1 (Kassomenos et al. 2001).

\subsection{Statistics}

Epidemiological time series models were fitted. In this type of analysis a time period, usually a day, is the research unit. The change in a health index is regressed against certain predictor or explanatory variables (the 'exposure' variables and confounders), which fluctuate on a daily basis. In this type of design, the short-term effects on health are examined (Schwartz et al. 1996, Samet et al. 1998, 2000, Katsouyanni et al. 1996, 2001, Touloumi et al. 2006).

The potential confounding variables included in our analysis were black smoke levels $\left(\mu \mathrm{g} \mathrm{m}^{-3}\right)$, temperature $\left({ }^{\circ} \mathrm{C}\right)$, dew point temperature $\left({ }^{\circ} \mathrm{C}\right)$, day of the week (6 dummy variables), year (8 dummy variables) and holidays (1 dummy variable).

Two types of analyses were applied:

(1) Multiple regression models using the logtransformed daily number of deaths as the dependent variable were used. Cosine and sine terms (trigonometric filtering) were included to control for seasonal- 
Table 1. Description of synoptic weather types in the Athens area (from Kassomenos et al. 2001)

\begin{tabular}{|c|c|c|}
\hline \multicolumn{2}{|c|}{ Synoptic weather type } & \multirow{2}{*}{$\begin{array}{l}\text { Weather conditions } \\
\text { Northwestern cold, dry winds }\end{array}$} \\
\hline $\mathrm{OC}$ & Open cyclone & \\
\hline SW & Southwesterly flow & Humid and warm air from the sea \\
\hline NW & Northwesterly flow & Cooler winds during summer, cold during winter, low relative humidity \\
\hline ZN & Zonal flow & Weak westerly/southwesterly winds \\
\hline $\mathrm{CC}$ & Closed cyclone & Strong, dry winds from the north \\
\hline OA & Open anticyclone & Persistent weak flows, moderate-to-low relative humidity and enhanced temperature \\
\hline $\mathrm{CA}$ & Closed anticyclone & Humid weak winds and temperature extremes \\
\hline HL & $\begin{array}{l}\text { Combination between a high } \\
\text { and a low pressure system }\end{array}$ & Moderate to strong northern or northeastern dry winds \\
\hline
\end{tabular}

ity. Different formulations were used to model the effect of temperature on mortality, such as linear or double quadratic, with the nadir at various temperatures between 20 and $30^{\circ} \mathrm{C}$, and the best fit (using the minimum mean square error [MSE] criterion) was obtained when $25^{\circ} \mathrm{C}$ was the turning point and 2 quadratic terms were used. Thus, temperature $(T)$ was included in the model by introducing 2 variables (hot) ${ }^{2}$ and (cold) $)^{2}$, where hot $=0$ if $T<25$ and hot $=T-25$ if $T \geq 25$, and cold $=25-T$ if $T<25$ and 0 otherwise. No transformation was necessary for dew point temperature. Climatic variables included in the model were $1 \mathrm{~d}$ lagged. Black smoke levels were introduced after $\log _{10}$ transformation and without lag, because this variable had the best fit (using the minimum MSE criterion) when compared with a linear term and lags of 2 to $5 \mathrm{~d}$. The residuals were tested for the presence of autocorrelation, and autoregressive terms were introduced as appropriate.

(2) We repeated the analysis using generalized additive models, accounting for overdispersion (quasilikelihood used), in R software (Wood 2000). We first fitted the base model, i.e. a model including the above potential confounders, and checked the residuals and then preceded with the introduction of the exposure variables in the model. We used penalized splines to control for seasonal and long-term trends. The degrees of freedom were chosen using the partial autocorrelation function (PACF) minimization criterion proposed by Touloumi et al. (2006). This procedure indicated 29 degrees of freedom to adequately control for seasonal and longterm trends. Temperature was also modelled using penalized splines. In this case, the degrees of freedom were chosen using the generalized cross-validation (GCV) criterion, and 8 degrees of freedom were found to be appropriate. In these models we also checked for autocorrelation in the residuals and included in the model appropriate autoregressive error terms (lagged residual series) (Schwartz et al. 1996, Brumback et al. 2000, Touloumi et al. 2004).

The effect of south winds on mortality was assessed using 3 variables, one indicating the presence of south winds during a particular day (blowing for $1 \mathrm{~h}$ or more), another for the duration (h) and a third representing the wind speed for $24 \mathrm{~h}\left(\mathrm{~m} \mathrm{~s}^{-1}\right)$. The synoptic category characterized by southwesterly flow is associated with daily mortality (Kassomenos et al. 2001), and it was included in the models in order to investigate the extent to which south winds affect health over and beyond the other variables.

\section{RESULTS}

Fig. 1 shows average daily mortality. There is a seasonal cycle, with a reliable peak in the winter months and more erratic shorter term peaks during summer months. In July 1987, mortality in Athens more than doubled when a heat wave struck Greece. This month was excluded as an outlier.

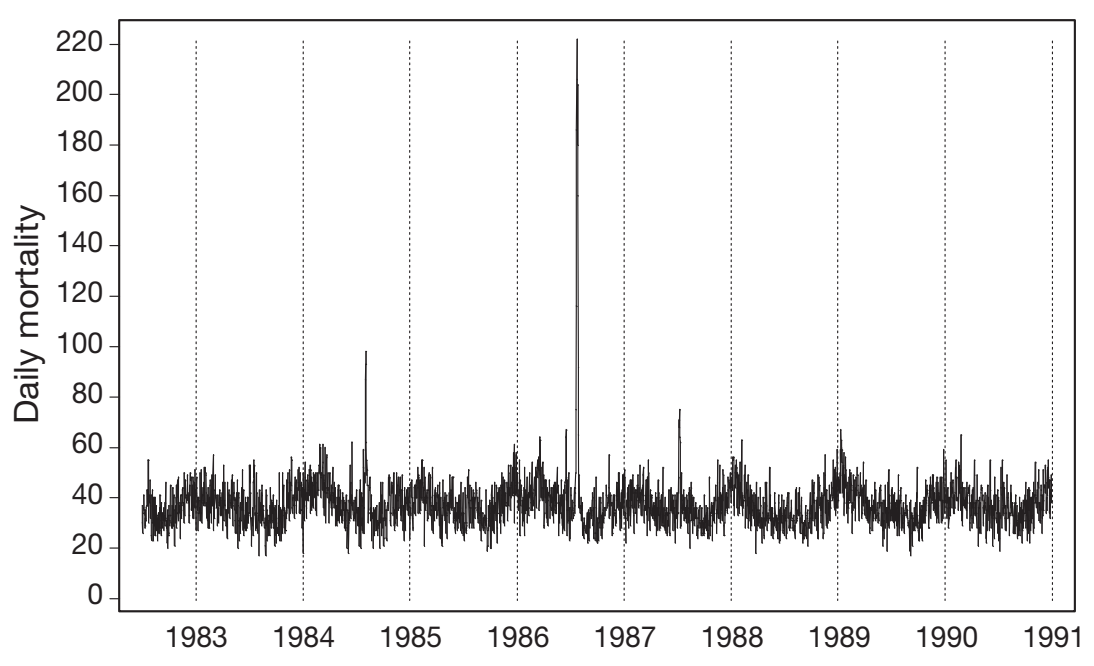

Fig. 1. Daily number of deaths during 1983-1991 in the Athens area 


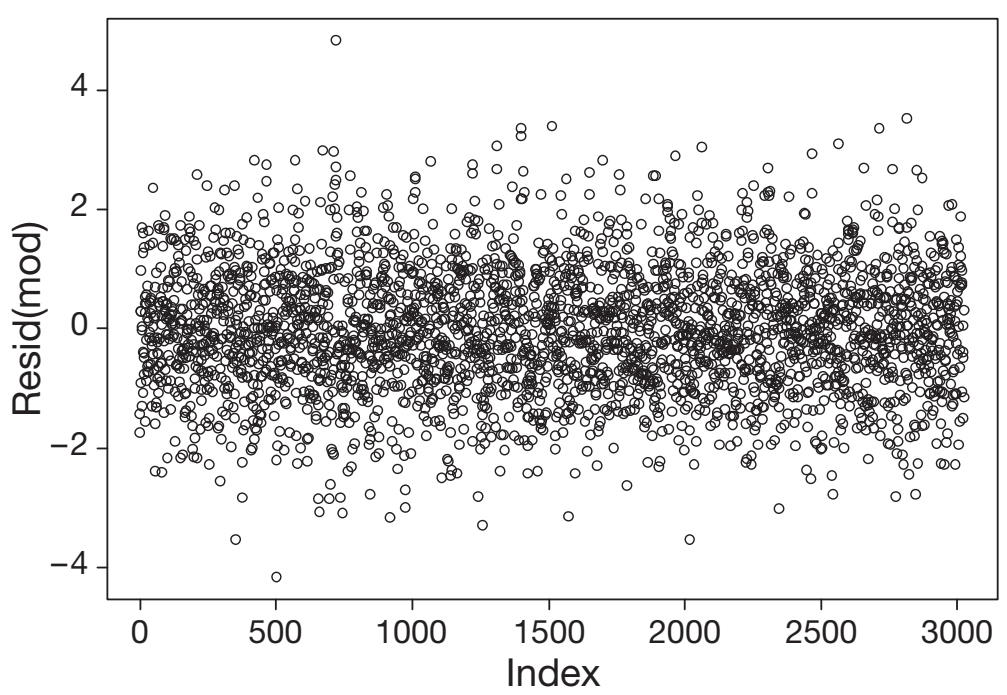

Fig. 2. Residuals of the fitted base model for the daily number of deaths adjusted for temperature, dew point temperature, year, season, day of the week and black smoke concentrations. Each circle represents the residual of one day

Table 2. Results of regression models investigating the association of the daily number of deaths with temperature, dew point temperature and black smoke concentration (adjusted for year, season and day of the week)

\begin{tabular}{|lccc|}
\hline & & $\begin{array}{c}\text { Relative } \\
\text { risk }\end{array}$ & $\begin{array}{c}\text { Confidence } \\
\text { interval }\end{array}$ \\
\hline Temperature (per $10^{\circ} \mathrm{C}$ change) & $(\mathrm{Hot})^{2}$ & 1.094 & $1.082-1.106$ \\
& $(\mathrm{Cold})^{2}$ & 1.004 & $1.003-1.006$ \\
Dew point temperature $\left({ }^{\circ} \mathrm{C}\right)$ & & 1.002 & $0.988-1.016$ \\
Log (Black Smoke) & $(95$ th vs. 5th percentile) & 1.070 & $1.043-1.099$ \\
\hline
\end{tabular}

The base model identified temperature as an important predictor of daily mortality (Table 2). There was no additional effect of dew point temperature on mortality. The estimated relative risk for mortality on a day with black smoke at the 95th percentile $\left(172 \mathrm{~g} \mathrm{~m}^{-3}\right)$ versus a day with levels at the 5th percentile $\left(28 \mathrm{~g} \mathrm{~m}^{-3}\right)$ was 1.07 . The introduction of second-order autoregressive terms was necessary to adjust for autocorrelation in the residuals. In Fig. 2 the plot of the residuals is shown, where no remaining pattern is evident.

Interactions between the presence of south winds and their duration and speed were also considered (Table 3). South winds were significantly associated with increased mortality by $3.2 \%$. When the duration of south winds and the speed were considered, higher values of both variables were associated with increased mortality. When the presence of southwesterly synoptic flow was added to the base model including south winds and their interaction with duration, both the presence of south winds and of the southwesterly synoptic flow had a highly significant effect. The final model presented in Table 3 includes only the base model confounders, the presence of south winds and that of southwesterly flow. The results show that mortality increases by $2.9 \%$ in days with south winds relative to days without south winds and by $3.6 \%$ in days

Table 3. Relative risks (RR) and 95\% confidence intervals (CI) for mortality from alternative second-order autoregressive models for variables indicating south winds or southwesterly flow when added to the base model (year, season, day of the week, temperature, dew point temperature and black smoke concentration) using 2 modelling approaches. Model 1: multiple regression model with log-transformed daily number of deaths as dependent variable, trigonometric filtering to adjust for seasonality, (hot) ${ }^{2}$ and $(\text { cold })^{2}$ for temperature, where hot $=0$ if $\mathrm{T}<25$ and hot $=\mathrm{T}-25$ if $\mathrm{T} \geq 25$, cold $=25-\mathrm{T}$ if $\mathrm{T}<25$ and 0 otherwise, and second order autoregressive error terms. Model 2: generalized additive models, accounting for overdispersion, using penalized splines (29 df) to adjust for seasonal and long-term trends and temperature ( $8 \mathrm{df}$ ) and second order autoregressive error terms

\begin{tabular}{|c|c|c|c|c|c|}
\hline & \multicolumn{2}{|c|}{ Model 1} & \multicolumn{2}{|c|}{ Model 2} & \multirow{2}{*}{$\begin{array}{c}\text { Deviance explained } \\
(\%)\end{array}$} \\
\hline & $\mathrm{RR}$ & $\mathrm{CI}$ & $\mathrm{RR}$ & $\mathrm{CI}$ & \\
\hline South winds (yes vs. no) & 1.032 & $1.014-1.051$ & 1.030 & $1.014-1.048$ & 33.4 \\
\hline South winds (yes vs. no) & 1.019 & $0.998-1.040$ & 1.014 & $0.995-1.034$ & 33.5 \\
\hline Duration of south winds (per $10 \mathrm{~h}$ ) & 1.001 & $1.000-1.003$ & 1.002 & $1.001-1.003$ & \\
\hline South winds (yes vs. no) & 1.014 & $0.987-1.041$ & 1.005 & $0.982-1.029$ & 33.4 \\
\hline Wind speed $\left(\mathrm{m} \mathrm{s}^{-1}\right)$ & 1.006 & $0.999-1.014$ & 1.010 & $1.003-1.016$ & \\
\hline South winds (yes vs. no) & 1.020 & $1.000-1.042$ & 1.016 & $0.996-1.036$ & 33.7 \\
\hline Duration of south winds (per $10 \mathrm{~h}$ ) & 1.001 & $1.000-1.002$ & 1.001 & $1.000-1.003$ & \\
\hline Southwesterly flow (yes vs. no) & 1.032 & $1.008-1.056$ & 1.016 & $0.996-1.036$ & \\
\hline South winds (yes vs. no) & 1.029 & $1.011-1.047$ & 1.028 & $1.011-1.045$ & 33.7 \\
\hline Southwesterly flow (yes vs. no) & 1.036 & $1.013-1.060$ & 1.040 & $1.018-1.062$ & \\
\hline
\end{tabular}


with southwesterly flow relative to days without. Table 3 also shows the results of the second analysis method, which are almost identical.

\section{DISCUSSION}

South winds - in terms of direction, duration and speed - might not be the 'cause' of adverse health effects, but they may be associated with other environmental factors (meteorological or not) that affect human health. In the present study, we adjusted for meteorological variables and other factors that affect mortality and found that the presence of south winds has an additional association with mortality in Athens. Thus, adjusting for temperature, dew point temperature, long-term trends, season, day of the week and synoptic weather categories was not adequate to remove the independent effect of south winds. We, therefore, conclude that other characteristics associated with the prevalence and severity of south wind affect mortality in the Athens area. These characteristics may be linked to the origin of these winds and/or to interactions with other environmental variables that are not completely understood and need further investigation.

Kassomenos et al. (2001) have pointed out the effect of the southwesterly synoptic category on daily mortality $(10 \%$ increase in the daily number of deaths; CI: 6.1 to $13.9 \%$ ). The influence of this synoptic category is linked to a rapid rise in temperature and relative humidity in the lower troposphere above the Aegean Sea, due to the differential between the hot, humid masses coming from North Africa over the Mediterranean Sea and the relatively dry, cool air masses above Greece. The resulting high temperatures for the time of year and the increased humidity apparently produce discomfort. Particularly when this occurs during the winter months, the southwesterly type hot, humid weather is in marked contrast to the prevailing and expected weather conditions (Kassomenos et al. 2001). This result is related to our findings that the presence and intensity of south winds has a further independent effect on the daily number of deaths.

Increased mortality has been observed at high as well as low temperature levels (Bai et al. 1995, Sartor et al. 1995, Ballester et al. 1997). A study conducted in 44 large cities in the USA demonstrated the effect of hot air masses on mortality (Kalkstein \& Greene 1997). Indeed, in the cold winter months, higher than usual temperatures were observed to exert a more rapid rise in mortality than lower temperatures (Ballester et al. 1997). This observation does not reverse the fact that cold weather, overall, produces a greater increase in mortality than hot weather. In a study of 7 regions of the European Union, including Athens, the annual mortality due to cold was 2003 per 1 million population and that due to heat was 217 per 1 million (Keatinge et al. 2000).

Concerning the effects of humidity, a study in Spain showed that the humidity levels might explain the observation that unusual temperature changes have a greater effect on mortality in the winter than in the summer (Saez et al. 1995). The effects of humidity are marked in tropical regions such as Sri Lanka, where seasonal fluctuations in mortality are associated with rainfall (Motohashi et al. 1996). In Australia, deaths increase with the colder and less humid weather associated with winds from a westerly direction (Auliciems et al. 1997).

In Athens, another major factor linked with south winds is atmospheric pollution, which is associated with increased morbidity and mortality (Katsouyanni et al. 2001). Within the framework of the present study, we adjusted for the concentration of suspended particles (the most important indicator of pollution associated with health effects) (Samet et al. 2000, Katsouyanni et al. 2001), and it was apparent that the association between south winds and mortality was independent of pollution, but we cannot exclude a certain degree of residual confounding.

However, in the present study, the effect of south winds on the increase in mortality was independent of the effects of high or low temperatures and dew point temperature, and of increased atmospheric pollutionas recorded by measurements of black smoke. These observations pose new questions about the interpretation of the phenomenon. What other factors, besides the above, associated with south winds, could be responsible for increased mortality? The answer to this question is beyond the scope of the present paper. Following the evidence provided here, which indicates that south winds are an independent predictor of mortality, and based on further study of cause-specific mortality and the pathogenic mechanisms of the diseases revealed to be most closely associated with mortality during south wind episodes, it will be possible to formulate specific hypotheses for further investigation.

\section{LITERATURE CITED}

Auliciems A, Frost D, Siskind V (1997) The time factor in mortality: weather associations in a subtropical environment. Int J Biometeorol 40:183-191

Bai H, Islam MN, Kuroki H, Honda K, Wakasugi C (1995) Deaths due to heat waves during the summer of 1994 in Osaka Prefecture, Japan. Nippon Hoigaku Zasshi 49: 265-274

Ballester F, Corella D, Perez-Hoyos S, Saez M, Hervas A (1997) Mortality as a function of temperature. A study in Valencia, Spain, 1991-1993. Int J Epidemiol 26:551-561

Brumback BA, Ryan LM, Schwartz JD, Neas LM, Stark PC, Burge HA (2000) Transitional regression models, with application to environmental time series. J Am Stat Assoc 
95:16-27

Curriero FC, Heiner KS, Samet JM, Zejer SL, Strug L, Patz JA (2002) Temperature and mortality in 11 cities of the eastern United States. Am J Epidemiol 155:80-87

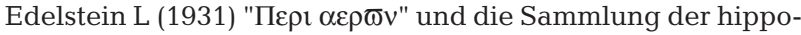
kratischen Schriften. Weidmann, Berlin

Kalkstein L (1991) A new approach to evaluate the impact of climate on human mortality. Environ Health Perspect 96: 145-150

Kalkstein LS, Greene JS (1997) An evaluation of climate/ mortality relationships in large U.S. cities and the possible impacts of a climate change. Environ Health Perspect 105: 84-93

Kassomenos P, Flocas HA, Lycoudis S, Skouloudis AN (1998) Spatial and temporal characteristics of the relationship between air quality status and mesoscale atmospheric circulation over an urban Mediterranean basin. Sci Total Environ 217:37-57

Kassomenos P, Gryparis A, Samoli E, Katsouyanni K, Lykoudis S, Flocas H (2001) Atmospheric circulation types and daily mortality in Athens, Greece. Environ Health Perspect 109:591-596

Katsouyanni K, Schwartz J, Spix C, Touloumi G and others (1996) Short term effects of air pollution on health: a European approach using epidemiologic time series data: the APHEA protocol. J Epidemiol Community Health 50(Suppl 1):S12-S18

Katsouyanni K, Touloumi G, Samoli E, Gryparis A and others (2001) Confounding and effect modification in the shortterm effects of ambient particles on total mortality: results from 29 European cities within the APHEA2 project. Epidemiology 12:521-531

Keatinge WR, Donaldson CG, Cordioli E, Kunst EA, Mackenbach PJ, Nayha S, Vuori I (2000) Heat related mortality in warm and cold regions of Europe: observational study. BMJ 321:670-673

Marmor M (1975) Heat wave mortality in New York City 1949-1970. Arch Environ Health 30:130-136

- Motohashi Y, Takano T, Nakamura K, Nakata K, Tanaka M (1996) Seasonality of mortality in Sri Lanka: biometeorological considerations. Int J Biometeorol 39:121-126

Olivieri A (1935) Libri medicinales. I-IV. Lipsiae et Berolini

Editorial responsibility: Mauricio Lima,

Santiago, Chile in Aedibvs B.G. Tevbneri. Corpus Medicorum Graecorum VIII, 1. Teubner, Leizpig

Pope CA III, Kalkstein LS (1996) Synoptic weather modeling and estimates of the exposure-response relationship between daily mortality and particulate air pollution. Environ Health Perspect 104:414-420

Saez M, Sunyer J, Castellsague J, Murillo C, Anto JM (1995) Relationship between weather, temperature and mortality: a time series analysis approach in Barcelona. Int $\mathrm{J}$ Epidemiol 24:576-582

Samet J, Zeger S, Kelsall J, Xu J, Kalkstein L (1998) Does weather confound or modify the association of particulate air pollution with mortality? Environ Res 77:9-19

Samet JM, Dominici F, Curiero FC, Coursac I, Zeger SL (2000) Fine particulate air pollution and mortality in 20 U.S. cities, 1987-1994. N Engl J Med 14, 343(24):1742-1749

Sartor F, Snacken R, Demuth C, Walckiers D (1995) Temperature, ambient ozone levels, and mortality during summer 1994, in Belgium. Environ Res 70:105-113

> Schwartz J, Spix C, Touloumi G, Bacharova L and others (1996) Methodological issues in studies of air pollution and daily counts of deaths or hospital admissions. J Epidemiol Community Health 50(Suppl 1):S3-S11

Sigerist H (1961) A history of medicine, Vol II. Oxford University Press, Oxford

The Eurowinter Group (1997) Cold exposure and winter mortality from ischaemic heart disease, cerebrovascular disease, respiratory disease, and all causes in warm and cold regions of Europe. Lancet 349:1341-1346

Touloumi G, Pocock S, Katsouyanni K, Trichopoulos D (1994) Short-term effects of air pollution on daily mortality in Athens: a time-series analysis. Int J Epidemiol 23:957-967

Touloumi G, Atkinson R, Le Tertre A, Samoli E and others (2004) Analysis of health outcome time series data in epidemiological studies. Environmetrics 15:101-117

$>$ Touloumi G, Samoli E, Pipikou M, Le Tertre A, Atkinson R, Katsouyanni K (2006) Seasonal confounding in air pollution and health time-series studies: effect on air pollution effect estimates. Stat Med 25:4164-4178

Wood SN (2000) Modelling and smoothing parameter estimation with multiple quadratic penalties. J R Statist Soc Ser B 62:413-428

Submitted: June 17, 2008; Accepted: November 6, 2008 Proofs received from author(s): February 19, 2009 